\title{
CHRONIC PAIN IS ASSOCIATED WITH FREQUENT USE OF EMERGENCY DEPARTMENT IN FRAIL OLDER ADULTS
}

Daniela Castelo Azevedo ${ }^{1, \star}$, Fernando César Menezes de Assunção ${ }^{1}$, Geraldo Barcellos de Camargo Neto ${ }^{1}$, Estevão Alves Valle ${ }^{1}$

1.Clínica Mais 60 Saúde, Belo Horizonte (MG), Brazil.

${ }^{\star}$ Corresponding author: az.dani@gmail.com

\section{BACKGROUND}

Elderly visits to emergency department (ED) seem to increase in the last years1 and can contribute to hospitalization and functional decline2. This is particularly concerning in the context of frailty, a state of vulnerability to poor resolution of homeostasis after a stressor event3. In young adults, chronic pain is associated with frequent use of ED services4. However, there is a paucity of literature evaluating this association in frail older adults, although chronic pain is frequent in this population, reaching $38.5 \%$ of prevalence5. This study investigated if chronic pain is associated with ED visits in frail older adults.

\section{MATERIALS AND METHODS}

This cross-sectional study was performed using data of older adults provided by an information and management system (LifeCode) used in a private geriatric outpatient clinic in Belo Horizonte (MG), Brazil. The patient ( $\geq 60$ years old) was considered frail if the Clinical-Functional Vulnerability Index-20 (IVCF-20) was $\geq 126$. Chronic pain was defined by the medical diagnosis of fibromyalgia, musculoskeletal chronic pain, low back pain or neuropathic pain in the LifeCode system. Frequent use of emergency department was defined by $>2$ visits in eight months (from April to December 2019). Multivariate binomial logistic regression was used to test for the associations of chronic pain with frequent ED visits. Analyses were adjusted for potential confounders age, sex, IVCF-20 and diagnosis of depression.

\section{RESULTS}

The sample comprised 3,666 frail older adults ( $79.7 \pm 8.5$ years, $74.9 \%$ female) with a mean of $4.9( \pm 2.9)$ diseases. The prevalence of chronic pain was $4.3 \%$. Chronic pain increased the odds of frequent $E D$ visits $(\mathrm{OR}=2.09 ; 95 \% \mathrm{Cl}=1.27-3.45)$, despite adjustment for all confounders.

\section{CONCLUSION}

The present study showed an independent association between chronic pain and frequent ED visits in frail older adults. Low prevalence of chronic pain was possibly related to underreporting. These findings corroborate the importance of identification and management of chronic pain in frail older adults to avoid possible adverse health outcomes related to ED visits.

\section{REFERENCES}

1. AlbertM, McCaig LF, Ashman JJ. Emergency department visits by persons aged 65 and over:United States, 2009-2010. NCHS data brief. 2013;130:1-8.

2. Aminzadeh F, Dalziel WB. Older adults in the emergency department: a systematic review of patterns of use, adverse outcomes, and effectiveness of interventions. Ann Emerg Med. 2002;39(3):238-47. https://doi.org/10.1067/mem.2002.121523

3. Clegg A, Young J, lliffe S, RikkertMO, Rockwood K. Frailty in elderly people. Lancet. 2013;381(9868):752. https://doi.org/10.1016/S0140-6736(12)62167-9

4. Dépelteau A, Racine-Hemmings F, LagueuxÉ, Hudon C. Chronic pain and frequent use of emergency department: A systematic review. Am J Emerg Med. 2020;38(2):358-63. https://doi.org/10.1016/j.ajem.2019.158492

5. Larsson C, Hansson EE, Sundquist K, Jakobsson U. Chronic pain in older adults: prevalence, incidence, and risk factors. Scand J Rheumatol. 2017;46(4):317-25. https://doi.org/10.1080/03009742.2016.1218543

6. Moraes EN, Carmo JA, Moraes FL, Azevedo RS, Machado CJ, Montilla DER. Clinical-Functional Vulnerability Index-20 (IVCF-20): rapid recognition of frail older adults. Rev Saúde Pública. 2016;50:81. http://doi.org/10.1590/s1518-8787.2016050006963 